Presented at the ASME International Mechanical Engineering Congress and Exposition, November 15-19, 1999, Nashville, Tennessee.

Published in Crashworthiness, Occupant Protection and Biomechanics in Transportation Systems, ASME, AMD Vol. 237/BED Vol. 45, 1999.

\title{
Crashworthiness Studies of Locomotive Wide Nose Short Hood Designs
}

\author{
David C. Tyrell and Eloy E. Martinez \\ Volpe National Transportation Systems Center \\ US Department of Transportation \\ Cambridge, MA 02142 USA \\ Tomasz Wierzbicki \\ Impact \& Crashworthiness Laboratory, \\ Massachusetts Institute of Technology, \\ Cambridge, Mass. 02139
}

\begin{abstract}
This paper investigates the parameters that influence the structural response of typical wide nose locomotive short hoods involved in offset collisions. This accident scenario was chosen based upon the railway collision that occurred in Selma, North Carolina, on May 16, 1994. A raised overhanging intermodal trailer on a freight car struck the front of the oncoming passenger locomotive. The objective of the study is to determine the current baseline level of crashworthiness of locomotive hood structures and the potential effectiveness of stronger corner structures. The key issues addressed are: degree of overlap, material and thickness combinations, obliquity, and crush response dependence on initial impacting speed. For a raised offset collision where the intruding body is far away from any support structures, an analytical expression is developed to predict the mean crush force. Comparisons of the results with finite element calculation are favorable. The scenarios involving obliquity, and different initial impacting speeds are investigated using non-linear large deformation finite element analyses. Key results are: obliquity has little effect on the mean crush force for short penetration distances; increased material thickness improves crashworthiness performance; initial impacting speed does not dramatically alter mean crush loads predicted for large offsets away from supports; and the distances from supporting structures have a significant effect of the predicted mode of failure and hence predicted mean crush loads. The results of the study show that it is possible to dramatically increase the crashworthiness responses of short hood structures with minor increases in weight while staying within the original design volume envelope.
\end{abstract}

\section{INTRODUCTION}

The collision scenario of concern is an offset collision between a raised intermodal trailer and a locomotive. The intermodal trailer engages and penetrates into the hood structure of the locomotive above the sub-base and outside the collision posts. An unfortunate example of this type of collision occurred in Selma, North Carolina, on May 16, 1994 (NTSB, 1995). An Amtrak passenger train collided with a raised intermodal trailer fouling its right of way. The closing speed of the accident was approximately $110 \mathrm{mph}$. Unfortunately during this accident, there was a loss of life and a large number of injuries.

Figure 1 shows the damage incurred to the locomotive during the accident. The locomotive was struck on the short hood, outboard of the collision post. The short hood is a shell structure that typically consists of multiple materials and thicknesses for the roof plates, sidewalls and forward facing front plates. The collision posts are relatively strong vertical members, attached to the main sill of the locomotive. The main sill in typical North American freight locomotives and in many passenger locomotives is a girder running the length of the locomotive. 
The engine, transformer, and operator's cab are attached to the top of the main sill. The main sill and collision posts are the principal structural supports for the short hood.
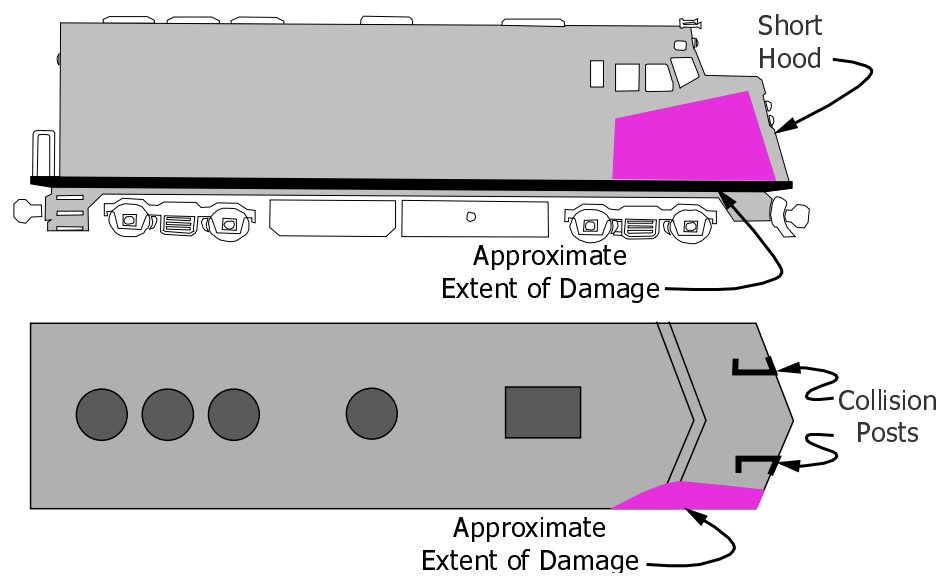

Figure 1. Damage incurred in lead locomotive during offset collision with intermodal trailer.

The aim of crashworthiness studies is to minimize the possibility of injuries or fatalities caused by the loss of occupant volume, and decelerations and force loads caused by secondary impacts. The design studies described in this paper were part of an effort to evaluate the influence of several design modifications on locomotive crashworthiness in five different collision scenarios (Tyrell, et al, 1999(a)). The results of the short hood design were used as input to a collision dynamics model to determine the response of the locomotive during an oblique collision with an intermodal container (Tyrell, et al, 1999(b)).

The objective of the present study is to investigate the essential parameters, which affect the crashworthiness performance of typical wide-nose short hood structures subjected to raking/oblique collisions. To assist in the validation of the modeling effort, an analytical expression is presented capable of predicting the mean crush resistance and energy absorption of thin walled shell structures loaded at a corner. There are four parameters investigated: degree of overlap, material and thickness combinations used to construct the hood structure, obliquity of collision, and the initial impacting speed. The analytical expression is applicable to the first two parameters listed.

The dynamic loading of the corner structure of the short hood is similar to the analysis of progressive crush of prismatic thin walled members. During a collision, the short hood crumples in an accordion fashion and then either ultimately fractures or globally collapses. There are numerous analytical and experimental studies addressing this problem for the automotive industry. Although there are similarities in the application of analytical design expressions developed to validate finite element analyses for the automotive industry, there are several essential differences between an automobile accident and a train accident. The crush zones in a train accident can be several orders of magnitude larger in comparison to an automobile accident. There are also scaling issues such as mass, size, and energies present for the different types of collisions.

The computational models used in current analyses of rail equipment collisions are validated either by conducting full-scale component tests, or through comparison of model predictions with accident consequences. Such testing can be expensive. The cost of an individual locomotive is approximately $\$ 2,000,000.00$. Also, there are usually gaps in the information available from accident consequences. Despite the differences associated with rail and automobile type accidents there is a need to establish analytical design expressions capable of predicting the mean crush resistance of locomotive sub-components. This paper discusses the formulation of such an expression as well as further investigations of other key parameters required to fully characterize the crashworthiness response of typical locomotive wide-nose short hoods.

A four phase approach is applied to this study:

- First, the application of energy methods to develop an analytical design expression capable of predicting the mean crush force of a simplified short hood geometry loaded in the corner is established.

- Next detailed dynamic, non-linear, large deformation, finite element models are constructed of a typical locomotive short hood. 
- Then comparisons of the computational and analytical models are conducted.

- Finally, for the cases where the analytical expression is not applicable, differences in response are explored using the finite element models

\section{ANALYTICAL DESIGN EQUATION}

Significant work has been done in the field of crashworthiness for the automotive industry in applying analytical design expressions to estimate mean crush loads expected during the progressive crush of thin walled members. A similar application towards the rail industry is possible. In the simplest sense, the short hood structure is a prismatic thin walled column. No cut outs are considered in this analysis. As mentioned earlier, the loading condition of concern is an offset, raised, corner loading of a large object penetrating into the hood structure. The intermodal trailer acts as a rigid object striking at normal incidence to the forward facing shell structure. Under this loading condition, the short hood is treated as a corner element (see Figure 2).

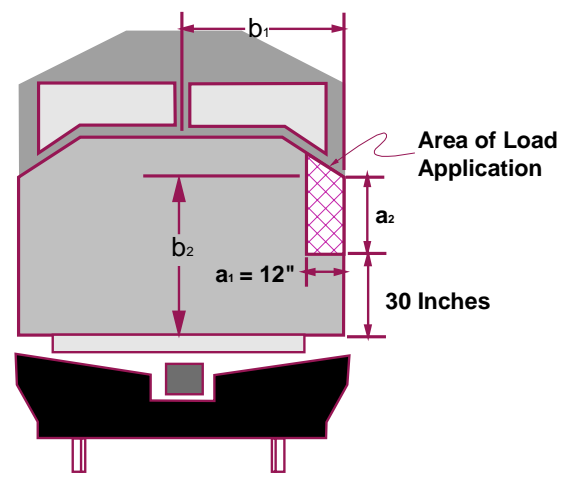

Figure 2. Offset loading condition of a typical wide-nose short hood.

An important assumption is that the corner element is isolated from the entire structure by two planes of symmetry. To begin, the intersecting roof and sidewalls of the hood structure are of a uniform thickness and material. The material is assumed to act rigid perfectly plastic and hence is described by a constant value for the flow stress, $\sigma_{o}$, which is treated as an average stress over a given range of strains. During the progressive collapse process, elastic strains are sufficiently small that they are ignored and the flow stress is averaged over the initial plastic strain and strain to fracture. Another assumption is that the length of the local plastic buckling wavelength, $2 \mathrm{H}$, remains constant during the crushing process. Figure 3 depicts a representative corner element at both initial undeformed and at intermediate deformed shapes.

$$
\mathbf{b}=\mathbf{b}_{1}+\mathbf{b}_{2}
$$

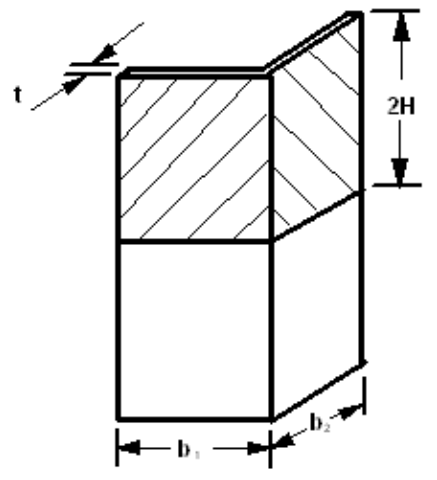

Initial Undeformed State

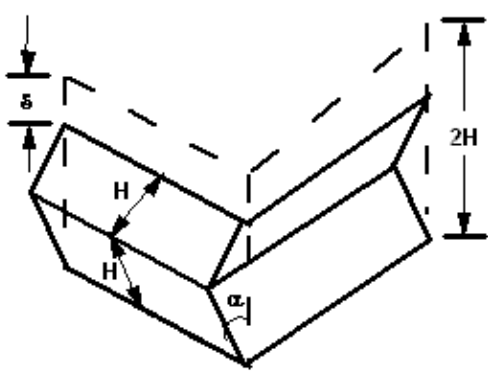

Intermediate Deformed State

Figure 3. A representative corner element subjected to uniaxial compressive load. 
There are three mechanisms in which the energy is consumed during the progressive crush of the corner element:

- membrane deformations which occur at the corner (or toroidal surfaces),

- $\quad$ bending deformations along stationary horizontal hinge lines, and

- bending/rebending or rolling deformations along the inclined plastic hinge lines.

Applying an energy balance during the crushing of the corner element with a plastic buckle wavelength of $2 H$, one obtains (Wierzbicki, and Abramowicz, 1983):

$$
P_{m} \frac{\delta_{e f f}}{2 H}=\frac{1}{4}\left[\sigma_{1} A_{1} r t+\sigma_{2} A_{2} \frac{b t^{2}}{H}+\sigma_{3} A_{3} \frac{H t^{2}}{r}\right]
$$

where $b=b_{1}+b_{2}$ is the composite length of the corner element and $r$ is the rolling radius measured at the bending/rebending inclined plastic hinge lines. For a detailed derivation of the energy balance, the reader is referred to the original paper by Wierzbicki and Abramowicz (1983). The left hand side of equation 1 represents the total work performed by the external forces in making one full fold. The coefficient $\delta_{e f f} / 2 H$ is the effective crush distance over which the external forces act. The effective crush distance is less than one-half the plastic buckle wavelength due to the finite folding radii which form. The right hand side is the sum of the internal plastic dissipation energies discussed above. The three coefficients, $A_{1}, A_{2}$, and $A_{3}$, arise from the integration of the rate of work energies over the deformation process.

The determination of the effective crush distance, $\delta_{\text {eff }} / 2 \mathrm{H}$, and the coefficients depend on the geometric properties of width to thickness ratio of the column. If one uses the von Karman definition of an effective width:

$$
\frac{b_{\text {eff }}}{t}=\sqrt{\frac{4 \pi E}{12\left(1-v^{2}\right) \sigma_{y}}}=1.9 \sqrt{\frac{E}{\sigma_{y}}}
$$

where $E$ is the Young's Modulus, $v$ is the Poisson ratio, and $\sigma_{\mathrm{y}}$ is the initial yield stress of the material, the following classification of columns can be introduced:

$$
\begin{array}{ll}
\text { Stocky (or thick) columns } & 0<\frac{b}{t}<20, \\
\text { Compact sections } & 20<\frac{b}{t}<\frac{b_{e f f}}{t}, \text { and } \\
\text { Non-compact sections } & \frac{b}{t}>\frac{b_{e f f}}{t} .
\end{array}
$$

The theory behind the energy balance presented applies to the range of compact sections. For example, in a typical mild steel, $E=2.1 \times 10^{5} \mathrm{MPa}, \sigma_{y}=210 \mathrm{MPa}$, and $b_{\text {eff }} / t=60$. However, the actual range typically encountered in short hood structures is $100 \leq b / t \leq 450$, which lies in the range of non-compact sections. The rigorous solution for non-compact sections is lacking in the literature, and hence empirical corrections are introduced to the solution of compact sections to extend its validity to non-compact sections.

The effective crush distance was calculated by Abramowicz and Wierzbicki (1989) to be approximately equal to $\delta_{\text {eff }} / 2 H=0.75$. For a single corner element, the coefficients that arise from the integration of rate of work energies over the deformation process are, $A_{1}=4.44, A_{2}=\pi$, and $A_{3}=2.3$. Finally, $\sigma_{1}, \sigma_{2}$, and $\sigma_{3}$ are average flow stresses in the respective regions. Upon substituting all numerical values into equation (1), the expression for the mean crushing force of one corner element takes the form:

$$
P_{m}=1.48 \sigma_{1} r t+\frac{\pi}{3} \sigma_{2} \frac{b t^{2}}{H}+0.77 \sigma_{3} \frac{H t^{2}}{r} .
$$

The input parameters on the right hand side of equation (3) are width and thickness of the corner element and the material data. $H$ and $r$ are still to be determined. It is postulated that these unknown parameters adjust themselves in the crushing process to minimize the mean crushing force. The analytical minimum of $P_{m}$ with respect to $H$ and $r$ exists and is found from: 


$$
\frac{\partial P_{m}}{\partial H}=\frac{\partial P_{m}}{\partial r}=0 .
$$

Solving the pair of non-linear simultaneous equations that result from the minimization, one obtains expressions explicitly in terms of $H$ and $r$, which are then substituted into equation (1) to yield:

$$
P_{m}=3.18\left[\sigma_{1} \sigma_{2} \sigma_{3}\right]^{1 / 3}\left[b t^{5}\right]^{1 / 3} \text {. }
$$

Application of the concept of equivalent flow stress reduces equation (5) to:

$$
P_{m}=3.18 \sigma_{o} b^{1 / 3} t^{5 / 3} \text {. }
$$

where

$$
\sigma_{o}=\sqrt[3]{\sigma_{1} \sigma_{2} \sigma_{3}}
$$

The equivalent flow stress also can be determined from the stress-strain curve (Wierzbicki and Schneider, 1999):

$$
\sigma_{o}=\sqrt[3]{\frac{\sigma_{y}^{2} \sigma_{u}}{1+n}}
$$

where $\sigma_{u}$ is the ultimate strength of the material and $n$ is the exponent of the power law representation of the stress-strain curve, $\sigma=A \varepsilon^{n}$, with typical values for the steels used in rail applications ranging between 0.1 and 0.2.

An approximate expression for the flow stress is given for ease of computation:

$$
\sigma_{o}=\sqrt{\sigma_{y} \sigma_{u}} .
$$

The authors suggest, pending further development of a rigorous theory for non-compact sections, the form of the solution remain the same for predicting the mean crush loads of the corner element. The key difference in the crush resistance of non-compact sections versus compact sections is due to the bending strains. The relatively thin wall thickness for non-compact sections develops smaller maximum and average strains along stationary plastic hinge lines. Another difference is that the location of the formation of inclined transient plastic hinge lines changes. Consequently, the expected deformed shape of the basic folding element also changes. The membrane strains are probably not affected. Due to these changes, both the effective crush distance, $\delta_{\text {eff }} / 2 \mathrm{H}$, and the plastic flow coefficients are expected to be different.

It is possible to extend this solution to allow for multiple thicknesses, i.e. the roof plate and the sidewalls of the short hood structure are of different thicknesses. It is postulated that during the crushing process the progressive folds alternate between the thinner and thicker flanges. This implies then that the mean crush load should be determined over two complete folds as opposed to a single fold. This is done by applying a weighted average over the two different wavelengths.

$$
P_{m}=P_{m}^{I} \frac{H_{I}}{H_{I}+H_{I I}}+P_{m}^{I I} \frac{H_{I I}}{H_{I}+H_{I I}}
$$

where $P_{m}{ }^{I}$ is the average force over the wavelength $2 H_{I}$ when the plastic hinges sweep through the flange of thickness $t_{l}$, and $P_{m}{ }^{I I}$ is the average force over the wavelength $2 H_{I I}$ when the plastic hinges sweep through the flange of thickness $t_{2}$. The mechanisms of corner compression and hinge rolling deformations are "feeling" one thickness only. At the same time, the bending deformations are split between the two flanges. Applying the energy balance technique and again solving for the unknown parameters of $H$ and $r$ one obtains three expressions for the two wavelengths and the rolling radius. Substituting those expressions into equation (10) and simplifying yields:

$$
P_{m}=3.18 \sigma_{o}\left[b_{1} t_{1}^{2}+b_{2} t_{2}^{2}\right]^{1 / 3} \frac{2 t_{1} t_{2}}{t_{1}+t_{2}} .
$$

There is symmetry to the solution as expected, as the subscripts 1 and 2 are interchangeable. In addition, for equal length and equal thickness flanges equation (11) simply reduces to the same expression as equation (6). An expression for multiple material properties has been developed using a similar approach.

The analysis conducted is strictly valid for symmetric crush. Symmetric crush occurs when the car-to-barrier interface moves as a rigid body parallel to the longitudinal axis of the vehicle and covers the entire front end. 
During an offset collision, the symmetry is lost. The intruding body pushes against the corner structure causing a considerable amount of membrane/shear deformation to develop.

It is postulated that the crushing strength of a thin walled column subjected to offset loading is one half the total strength of the entire four-corner column calculated for symmetric crush. This postulate is based upon the observation that two sides of the column are activated and fold while the remaining two sides remain undeformed. The additional resistance comes from shear deformations in the transition zones between the displaced corner and the stationary supporting structure. Thus, for the present application, equations (6) and (11) should be multiplied by a factor of two:

$$
\begin{aligned}
& P_{m}=6.36 \sigma_{o} b^{1 / 3} t^{5 / 3} \\
& P_{m}=6.36 \sigma_{o}\left[b_{1} t_{1}^{2}+b_{2} t_{2}^{2}\right]^{1 / 3} \frac{2 t_{1} t_{2}}{t_{1}+t_{2}}
\end{aligned}
$$

Preliminary results from a companion study have substantiated this result for $b / t>100$ (Wierzbicki and Rudolph, 1999).

\section{FINITE ELEMENT MODEL}

The geometrical details of the wide-nose short hood and the impacting object used in the finite element model are depicted in Figure 4. The finite element model is constructed from 5960 4-noded reduced integration shell elements. The full short hood was modeled including the pair of collision posts. The attachment of the hood structure and collision posts to the sub-base was simplified to a fixed boundary condition; the stiffness of the subbase is at least an order of magnitude higher then the superstructure. The hood structure is unrestrained in the rear above the attachment to the sub-base. All materials are modeled as elastic-plastic with kinematic hardening. Kinematic hardening is calculated using a von Mises yield surface. Failure of an element is allowed using a damage plasticity model where at a given strain the element accumulates damage and looses stiffness. At complete failure, the element is removed from the calculation. During the crushing event, the hood crumples similar to an accordion. The amplitude of the buckle wavelengths depends on where the hood is struck. Doublesided contact is calculated to model the self-contact between folds. The intruding object is constructed from rigidized shell elements representing the intermodal trailer.

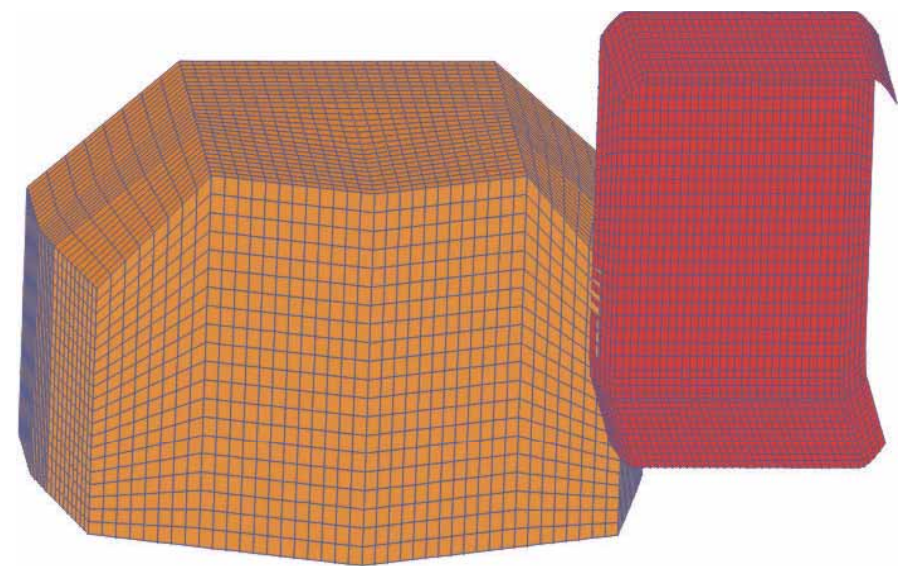

Figure 4. Schematic of wide nose locomotive short hood finite element model.

The short hood has many cutouts in it, but the industry standards dictate that any loss in stiffness due to a cutout be compensated for by adding special framing members and/or reinforcing brackets. Also there are typically non-structural items and connections under the hood which are not accounted for in these models. The purpose of the development of the simplified design expression and the finite element models is to determine the qualitative trends of the short hood response. 
An auxiliary node was defined on the rigid impactor through which an initial velocity could be defined. This auxiliary node was constrained such that only translational motion is allowed. The rigid impacting object is assigned a mass depending on the particular analysis. Assigning an initial velocity to the mass provides the initial kinetic energy for the collision.

A series of analyses were conducted using ABAQUS Explicit (Hibbit, Karlsson and Sorensen, Inc., 1998) to ensure convergence of the solution, using various mesh refinements on a simplified model. The final mesh was chosen based upon solution convergence and CPU usage.

There are five materials used in this study, and the material properties are summarized below in Table 1. Material type 5 has a sufficiently high strength that it has a reduced strain to fracture compared with the other four materials. Young's Modulus, Poisson's ratio, and materials density are constant and values typical for structural steels were used: $E=2.1 \times 10^{5} \mathrm{MPa}\left(30 \times 10^{6} \mathrm{psi}\right), v=0.3$, and $\rho=7850 \mathrm{Kg} / \mathrm{m}^{3}\left(15.2 \mathrm{slugs} / \mathrm{ft}^{3}\right)$.

Table 1. Material properties used in analyses.

\begin{tabular}{|c|c|c|c|}
\hline $\begin{array}{c}\text { Material } \\
\text { No }\end{array}$ & $\begin{array}{c}\text { Nominal Yield } \\
\text { Strength }\end{array}$ & $\begin{array}{c}\text { Nominal Ultimate } \\
\text { Strength (ksi) }\end{array}$ & $\begin{array}{c}\text { Strain to } \\
\text { Fracture }\end{array}$ \\
\hline 1 & $172 \mathrm{MPa}(25 \mathrm{ksi})$ & $310 \mathrm{MPa}(45 \mathrm{ksi})$ & 0.35 \\
\hline 2 & $186 \mathrm{MPa}(27 \mathrm{ksi})$ & $310 \mathrm{MPa}(45 \mathrm{ksi})$ & 0.35 \\
\hline 3 & $248 \mathrm{MPa}(36 \mathrm{ksi})$ & $345 \mathrm{MPa}(50 \mathrm{ksi})$ & 0.35 \\
\hline 4 & $345 \mathrm{MPa}(50 \mathrm{ksi})$ & $483 \mathrm{MPa}(70 \mathrm{ksi})$ & 0.35 \\
\hline 5 & $689 \mathrm{MPa}(100 \mathrm{ksi})$ & $827 \mathrm{MPa}(120 \mathrm{ksi})$ & 0.20 \\
\hline
\end{tabular}

Figure 5 depicts a typical force/crush curve obtained using the mesh design described above. This particular analysis was for a design with one-half inch thick forward facing plates and sidewalls made from a $248 \mathrm{MPa}$ (36 ksi) nominal yield strength material. The roof was one-quarter inch thick using a $186 \mathrm{MPa}(27 \mathrm{ksi})$ nominal yield strength material. The curve was drawn using a sampling rate of $0.0001 /$ seconds in the history output for nodal positions, strains, and stresses. To determine an average crush force for a given crush distance, a running average is taken out to $1.02 \mathrm{~m}$ (40 inches) of crush where rear hood boundary conditions had negligible effects.

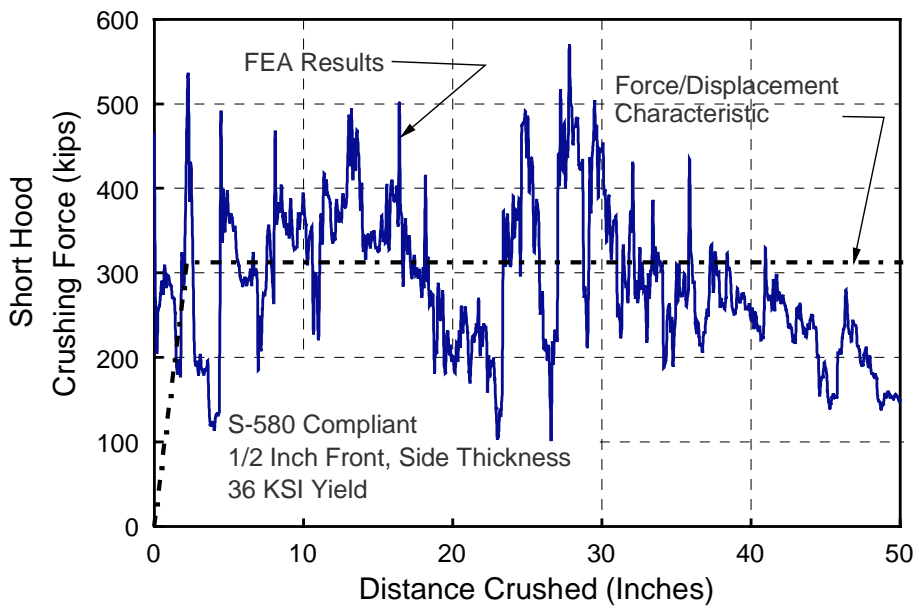

Figure 5. Typical force/crush characteristic for an offset oblique collision.

The details of the force time history during the right angle impact do not have an influence on the trajectories of the impacting bodies. The principal influence on the trajectory of the bodies is the transfer of momentum from one body to another. Accordingly, the force crush characteristic from the finite element analysis is smoothed to produce the force/displacement characteristic for the input to the collision dynamics model (Tyrell, et al 1999(b)). 


\section{ANALYSES RESULTS}

As discussed earlier there are four parameters studied:

- different materials/thickness combinations,

- degree of overlap,

- obliquity, and

- initial impacting speed.

The developed analytical design expression is capable of predicting mean crush force for different materials and thicknesses. The discussion of the results obtained using the analytical design expression and comparisons with analyses using the finite element methodology follow.

\section{Material/Thickness Combinations and Overlap, Closed Form and FEA Analysis}

For a given hood geometry, comparisons can be made between the analytical design expression and the finite element results for those cases which are sufficiently removed from support structures. This section outlines the results obtained using both the analytical design expression and those obtained using the finite element methodology.

\section{Material Thickness}

The locomotive short hood structure analyzed with the analytical design expression has a fixed geometry with the only parameters varied being material and thickness. The approximate hood length is $1.83 \mathrm{~m}$ (72 inches), with a width of $3.05 \mathrm{~m}$ (120 inches), by a height of $1.285 \mathrm{~m}$ (50.6 inches). Since the hood was idealized as rectangular, $b_{1}$ is not equal to $b_{2}$ (see Figure 2), equation 10 must be used to calculate the predicted mean crush force. Figure 6 shows the relationship established between mean crush force and varying thickness for materials $1,3,4$, and 5 defined in Table 1.

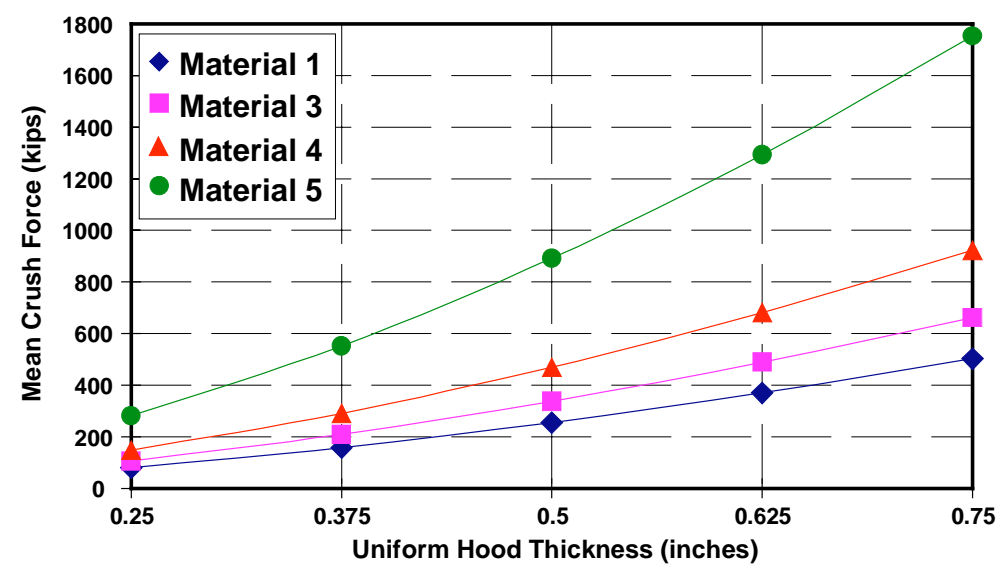

\section{Figure 6. Variation in predicted mean crush force with thickness obtained using the design equation.}

Once the corner element is engaged in a right angle impact event progressive folding initiates and shear bands form assisting the structure to absorb the collision energy. As expected, there is a non-linear increase in the predicted mean crush force with thickness. Simplifying equation 13 to equation 12 for a square column loaded in an offset manner one notes that there is a dependency on the thickness by a power raised to the factor $5 / 3$. The predicted mean crush force also increases with the use of stronger materials because of the linear dependency on the flow stress, $\sigma_{\mathrm{o}}$. The calculation for the equivalent flow stress, $\sigma_{\mathrm{o}}$, does not account for any loss in ductility and hence the strongest material predicts the highest mean crush load at the largest thickness presented. The calculations performed with the finite element model account for fracture using the equivalent plastic strain to fracture. Consequently, it is expected that the results obtained from the finite element calculations will result in a lower mean crush force with the use of low ductility materials. 


\section{Material and Thickness Combinations}

Table 2 summarizes the material and thickness variations for the short hood designs investigated to determine effects of material parameters on crush response. The current industry practice follows a standard that stipulates "the thickness of the material forward facing on the short hood must be inversely proportional to the square root of the materials yield strength" (Association of American Railroads, 1989). In practice, this requirement has been interpreted to mean that the front and sidewalls are constructed of the same material while the roof material may have a different yield strength and thickness and that both the roof and sidewalls may be constructed from materials with different yield strengths and thick nesses from the front material.

The first interpretation referred to as design A, results in a design for the roof with $6.35 \mathrm{~mm}(0.25 \mathrm{inch})$ thick plate and a nominal $186 \mathrm{MPa}(27 \mathrm{ksi})$ yield material. The second interpretation to the regulation, referred to as design $\mathrm{B}$, allows for a design where the roof and sidewalls are constructed of a uniform $4.7625 \mathrm{~mm}(0.1875 \mathrm{inch})$ plate with a nominal $186 \mathrm{MPa}(27 \mathrm{ksi})$ yield strength material. Another interpretation, referred to as design C, dictates that the hood shall be constructed from both uniform materials and a single thickness obtained from S-580 requirements. The final set of designs proposed, design $\mathrm{D}$, use both a uniform material and a uniform $19.05 \mathrm{~mm}$ ( 0.75 inch) thickness for the roof, sidewalls, and the forward facing plates. This last design is chosen to demonstrate the extent in increased crashworthiness performance with a simple change in geometry.

All these analyses have an offset position of the rigid penetrating body defined as $355.6 \mathrm{~mm}$ (14 inches) outside the inner corner of the collision post and $762 \mathrm{~mm}$ (30 inches) above the sub-base. The initial velocity assigned to the auxiliary mass was $80 \mathrm{~km} / \mathrm{h}(50 \mathrm{mph})$, and the initial mass assigned was $27216 \mathrm{Kg}(60000 \mathrm{lbs}$.). The approximate hood length is $1.83 \mathrm{~m}$ (72 inches), with a width of $3.05 \mathrm{~m}$ (120 inches), by a height of $1.285 \mathrm{~m}$ (50.6 inches).

Table 2. Material and thickness combinations of short hood designs studied.

\begin{tabular}{|c|c|c|c|}
\hline$\frac{\text { Design/Case }}{\text { No. }}$ & $\frac{\text { Forward Facing }}{\text { Plates }}$ & Sidewalls & Roof \\
\hline A-1 & $25 \mathrm{ksi} / 0.5 ”$ & $25 \mathrm{ksi} / 0.25^{\prime \prime}$ & $27 \mathrm{ksi} / 0.25^{\prime \prime}$ \\
\hline B-1 & $25 \mathrm{ksi} / 0.5^{\prime \prime}$ & $25 \mathrm{ksi} / 0.1875^{\prime \prime}$ & $27 \mathrm{ksi} / 0.1875^{\prime \prime}$ \\
\hline C-1 & $25 \mathrm{ksi} / 0.5$ & $25 \mathrm{ksi} / 0.5$ & $25 \mathrm{ksi} / 0.5^{\prime \prime}$ \\
\hline D-1 & $25 \mathrm{ksi} / 0.75^{\prime \prime}$ & $25 \mathrm{ksi} / 0.75^{\prime \prime}$ & $25 \mathrm{ksi} / 0.75^{\prime \prime}$ \\
\hline A-2 & 36 ksi/0.5" & $36 \mathrm{ksi} / 0.25$ " & $27 \mathrm{ksi} / 0.25$ " \\
\hline B-2 & $36 \mathrm{ksi} / 0.5$ & $36 \mathrm{ksi} / 0.1875^{\prime \prime}$ & $27 \mathrm{ksi} / 0.1875^{\prime \prime}$ \\
\hline $\mathrm{C}-2$ & $36 \mathrm{ksi} / 0.5^{\prime \prime}$ & $36 \mathrm{ksi} / 0.5 "$ & $36 \mathrm{ksi} / 0.5 "$ \\
\hline D-2 & 36 ksi/0.75" & $36 \mathrm{ksi} / 0.75^{\prime \prime}$ & $36 \mathrm{ksi} / 0.75^{\prime \prime}$ \\
\hline A-3 & $50 \mathrm{ksi} / 0.375^{\prime \prime}$ & $50 \mathrm{ksi} / 0.25 "$ & $27 \mathrm{ksi} / 0.25 "$ \\
\hline B-3 & $50 \mathrm{ksi} / 0.375^{\prime \prime}$ & $50 \mathrm{ksi} / 0.1875^{\prime \prime}$ & $27 \mathrm{ksi} / 0.1875^{\prime \prime}$ \\
\hline $\mathrm{C}-3$ & $50 \mathrm{ksi} / 0.375^{\prime \prime}$ & 50 ksi/0.375" & $50 \mathrm{ksi} / 0.375^{\prime \prime}$ \\
\hline D-3 & 50 ksi/0.75" & $50 \mathrm{ksi} / 0.75^{\prime \prime}$ & $50 \mathrm{ksi} / 0.75^{\prime \prime}$ \\
\hline A-4 & $100 \mathrm{ksi} / 0.25 "$ & 100 ksi/0.25” & 27 ksi/0.25" \\
\hline B-4 & $100 \mathrm{ksi} / 0.25 "$ & $100 \mathrm{ksi} / 0.1875^{\prime \prime}$ & $27 \mathrm{ksi} / 0.1875^{\prime \prime}$ \\
\hline $\mathrm{C}-4$ & $100 \mathrm{ksi} / 0.25 "$ & 100 ksi/0.25" & $100 \mathrm{ksi} / 0.25$ \\
\hline D-4 & $100 \mathrm{ksi} / 0.75 "$ & $100 \mathrm{ksi} / 0.75^{\prime \prime}$ & $100 \mathrm{ksi} / 0.75 "$ \\
\hline
\end{tabular}

Figure 7 shows the comparison in predicted response between the analytical design expression and the finite element analysis for designs A and B. The analytical model stays consistently within twenty percent of the calculated finite element results.

These design cases are all very non-compact and the results obtained using the analytical design expression can be improved on by further investigations into the folding patterns that this type of column exhibits. Changes in the predicted results in this regime could occur if there is a substantial difference in the actual effective crush distance. These very thin shell sections develop smaller bending/rebending strains and the positions where the static plastic horizontal hinge lines form during crush of a symmetric corner element change. This change in geometry was not fully investigated, but it is possible that the actual effective crush distance is smaller than the one used based upon compact sections. A smaller effective crush distance would increase the predicted mean crush force in an analogous development to that presented earlier. 

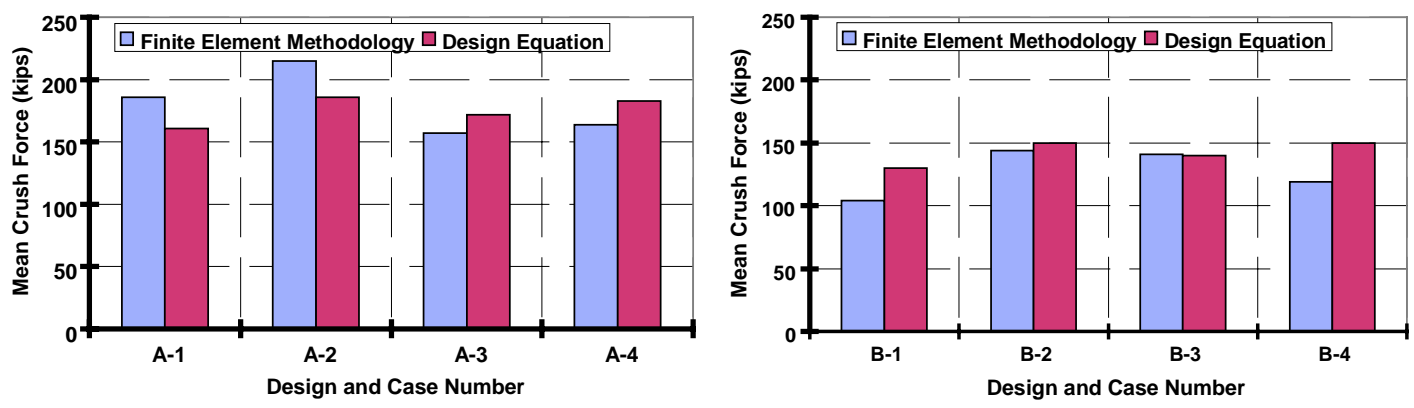

Figure 7. Variation in predicted crush response with material and thickness combinations for hood designs $A$ and $B$.

As described previously, the $689 \mathrm{MPa}(100 \mathrm{ksi})$ yield strength material is less ductile then the mild steels, for which the analytical design expression was developed for and has a propensity to fracture. Both design sets A and B Case 4 consistently over predict the mean crush force. The finite-element analysis results indicate large regions of material failure, so one expects the finite element results to predict a lower mean crush force.

Figure 8 depicts the differences in predicted response between the analytical design expression and the finite element analysis for the design sets $\mathrm{C}$ and $\mathrm{D}$. There is even closer correlation in results for the uniform thickness hood designs for design set $\mathrm{C}$ except for the $689 \mathrm{MPa}(100 \mathrm{ksi})$ design case. The analytical design expression is not conservative for all cases of design set D. Thick plates, especially those with a relatively low strain to fracture, may fracture prior to full formation of the bending/rebending hinge lines due to the large strains experienced. If fracture occurs, it decreases the relative stiffness of the system and the actual response should exhibit a smaller mean crush force.
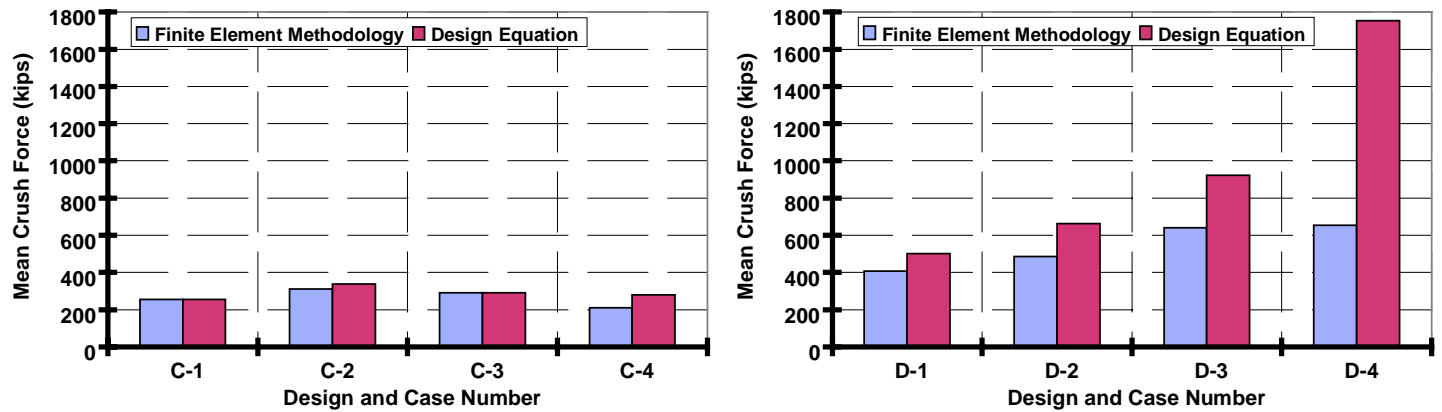

Figure 8. Variation in predicted crush response with material and thickness combinations for hood designs $C$ and $D$.

Based upon these analyses, the range of thicknesses for general locomotive short hood designs for which the analytical design expression is most applicable is from 6.35 to $15.875 \mathrm{~mm}$ ( 0.25 to 0.625 inches), depending on the type of material chosen for the hood.

\section{Uniform Material and Multiple Thickness Combinations}

The set of analyses conducted to test the applicability of the analytical design expression to multiple thickness components constructed from a single uniform material, a nominal minimum yield strength of $172 \mathrm{MPa}$ (25 ksi), are summarized in Table 3. The forward facing plates are all uniform $12.7 \mathrm{~mm}(0.5 \mathrm{inch})$ in thickness. All these analyses have an offset position of the rigid penetrating body defined as $355.6 \mathrm{~mm}$ (14 inches) outside the inner corner of the collision post and $762 \mathrm{~mm}$ (30 inches) above the sub-base. The approximate hood length is $1.83 \mathrm{~m}$ (72 inches), with a width of $3.05 \mathrm{~m}$ (120 inches), by a height of $1.285 \mathrm{~m}$ (50.6 inches). The initial velocity assigned to the auxiliary mass was $80 \mathrm{~km} / \mathrm{h}(50 \mathrm{mph})$, and the initial mass assigned was $27216 \mathrm{Kg}(60000 \mathrm{lbs}$.). 
Table 3. Multiple thickness uniform material designs.

\begin{tabular}{|c|c|c|c|}
\hline $\begin{array}{c}\text { Case } \\
\text { No. }\end{array}$ & $\begin{array}{c}\text { Front } \\
\text { Plates }\end{array}$ & $\begin{array}{c}\text { Roof } \\
\text { Plates }\end{array}$ & $\begin{array}{c}\text { Side } \\
\text { Walls }\end{array}$ \\
\hline 1 & $12.7 \mathrm{~mm}(0.5$ inches $)$ & $12.7 \mathrm{~mm}(0.5$ inches $)$ & $12.7 \mathrm{~mm}(0.5$ inches $)$ \\
\hline 2 & $12.7 \mathrm{~mm}(0.5$ inches $)$ & $9.53 \mathrm{~mm}(0.375$ inches $)$ & $12.7 \mathrm{~mm}(0.5$ inches $)$ \\
\hline 3 & $12.7 \mathrm{~mm}(0.5$ inches $)$ & $6.35 \mathrm{~mm}(0.25$ inches $)$ & $9.53 \mathrm{~mm}(0.375$ inches $)$ \\
\hline 4 & $12.7 \mathrm{~mm}(0.5$ inches $)$ & $4.76 \mathrm{~mm}(0.1875$ inches $)$ & $9.53 \mathrm{~mm}(0.375$ inches $)$ \\
\hline
\end{tabular}

Figure 9 depicts the predicted response for both the analytical design expression and the finite element methodology. The analytical design expression predictions for cases 1 and 2 are within four percent of the predictions given by the finite element analysis. The mean crush force predictions are conservative for designs 3 and 4. The force levels predicted using the finite element analysis are lower than those predicted using the design equation. The relative width to thickness ratio for these designs are extremely non-compact where the analytical design expression needs further refinement. The thicker the shell structure, the greater the predicted mean crush force.

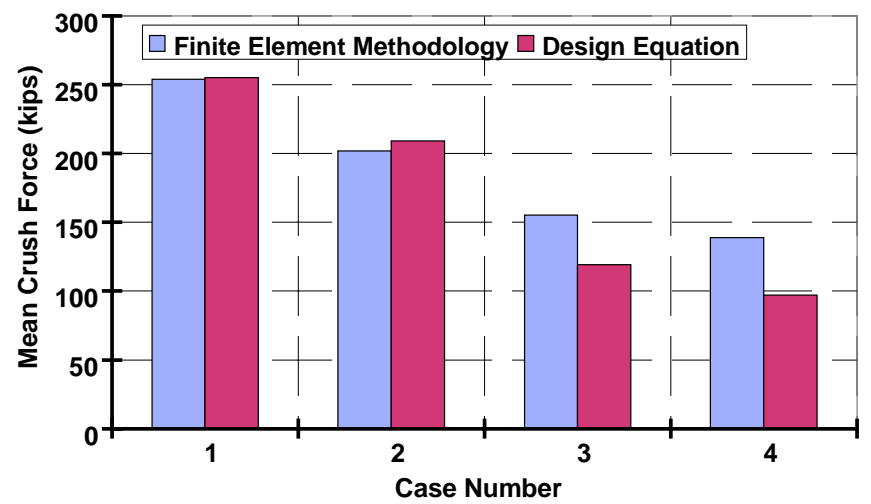

Figure 9. Variation in crush response of multiple thickness uniform material designs.

\section{Offset}

A single design was developed and the spatial positions varied to investigate changes in predicted response with the degree of overlap using the finite element methodology. The spatial positions varied are presented in Table 4. The positions listed in the table are defined with respect to either the distance outside the inner corner of the collision posts or the height measurement above the sub-base. The design equations (12) and (13) are not sensitive to the degree of overlap. They were developed to address the general response of a corner element subjected to a uniaxial load.

The hood design chosen was a uniform material throughout the hood with nominal yield strength of $345 \mathrm{MPa}$ (50 ksi). The thickness of the hood shell structure is kept constant, and the thickness was varied between: 6.35 $\mathrm{mm}$ (0.25 inches), $9.53 \mathrm{~mm}$ (0.375 inches), $12.7 \mathrm{~mm}$ (0.5inches), $15.875 \mathrm{~mm}$ (0.625 inches), and $19.05 \mathrm{~mm}(0.75$ inches). The initial velocity assigned to the auxiliary mass was $80 \mathrm{~km} / \mathrm{h}(50 \mathrm{mph})$, and the initial mass assigned was $27216 \mathrm{Kg}$ (60000 lbs.).

Table 4. Spatial positions defining the degree of overlap.

\begin{tabular}{|c|c|c|}
\hline $\begin{array}{c}\text { Case } \\
\text { No. }\end{array}$ & $\begin{array}{c}\text { Outside Collision } \\
\text { Post }\end{array}$ & $\begin{array}{c}\text { Above } \\
\text { Sub-base }\end{array}$ \\
\hline 1 & $203.2 \mathrm{~mm}(8$ inches $)$ & $381 \mathrm{~mm}(15$ inches $)$ \\
\hline 2 & $203.2 \mathrm{~mm}(8$ inches $)$ & $762 \mathrm{~mm}(30$ inches $)$ \\
\hline 3 & $355.6 \mathrm{~mm}(14$ inches $)$ & $381 \mathrm{~mm}(15$ inches $)$ \\
\hline 4 & $355.6 \mathrm{~mm}(14$ inches $)$ & $762 \mathrm{~mm}(30$ inches $)$ \\
\hline
\end{tabular}

The results predicted using the finite element models are presented in Figure 10. The same trend of predicting a greater mean crush force with an increase in thickness is demonstrated. The analytical design expression performs well for thinner thickness hoods then over predicts the mean crush force for the largest 
thicknesses. The finite element analysis results show large regions of material failure for the thickest hoods. Fracture is not accounted for in the analytical design expression. If fracture occurs, it decreases the relative stiffness of the system and the actual response should exhibit a smaller mean crush force.

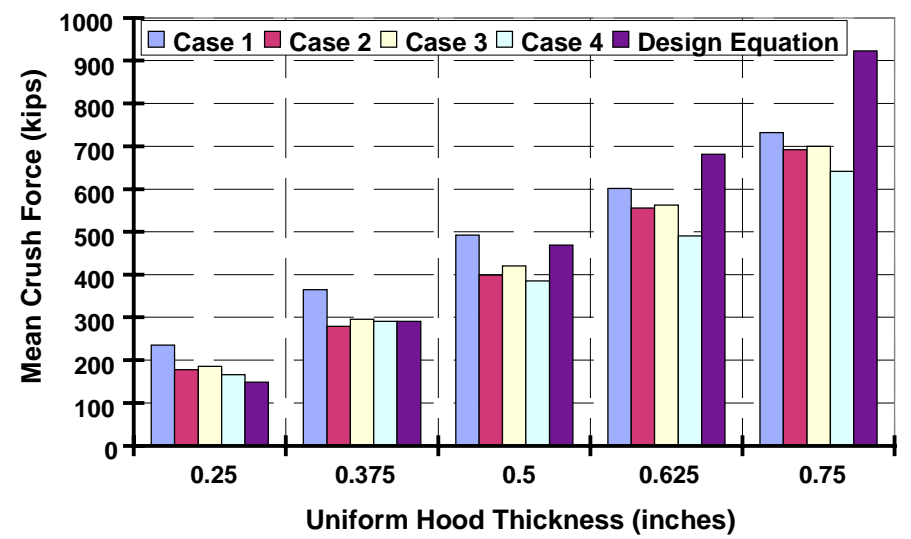

Figure 10. Comparison of variation in predicted mean crush force with degree of overlap obtained with the finite element analysis and the design equation.

The finite element analysis results indicate a weak dependence on degree of overlap for overlap Case 1. As the penetrating object approaches both support structures, the stiffness of the structure increases. The propensity for fracture also increases as the impacting object approaches a support structure, and there appears to be a transition to a punching/tearing failure mode. Hence, the calculated mean crush force decreases for overlap conditions within a few inches of the collision post and above the sub-base. The mean crush force is insensitive to the initial overlap positions of the rigid object defined by Cases 2, 3, and 4. This substantiates the use of the analytical design expression for initial contact positions sufficiently removed from any support conditions.

Based upon these analyses, the range of thicknesses for general locomotive short hood designs for which the analytical design expression is most applicable is from 9.53 to $15.875 \mathrm{~mm}$ ( 0.375 to 0.625 inches) for a nominal minimum yield strength material of $345 \mathrm{MPa}(50 \mathrm{ksi})$. There may be differences in the applicable thickness range for milder steels; there may be even greater differences for high strength low ductility steels due to the propensity for fracture.

\section{Obliquity and Closing Speed, FEA Analysis}

Obliquity

A single design is developed for the obliquity analyses. The approximate hood length is $1.83 \mathrm{~m}$ (72 inches), with a width of $3.05 \mathrm{~m}$ (120 inches), by a height of $1.285 \mathrm{~m}$ (50.6 inches). The collision posts are the typical nominal minimum yield strength $345 \mathrm{MPa}(50 \mathrm{ksi})$ material and $31.75 \mathrm{~mm}(1.25$ inches $)$ thick. They are fully attached at the level of the sub-base and fully integrated with the intersecting shell structure of the hood. The front plates and the sidewalls are $9.52 \mathrm{~mm}(0.375$ inches $)$ thick and the material is a nominal minimum yield strength of $345 \mathrm{MPa}(50 \mathrm{ksi})$. The roof is $6.35 \mathrm{~mm}(0.25$ inches $)$ thick and constructed from material with a nominal minimum yield strength of $186 \mathrm{MPa}(27 \mathrm{ksi})$. The auxiliary node on the impacting body is assigned a mass of $27,215 \mathrm{Kg}(60,000 \mathrm{lbs}$.) and an initial velocity of $80 \mathrm{~km} / \mathrm{h}(50 \mathrm{mph})$.

The angles at which the rigidized impacting body strikes the hood structure are described in Table 5. The degree of overlap is maintained constant for the normal and side impact cases. The shape of the hood is different in these two directions, but for short penetration distances it is expected that the predicted mean crush forces will be comparable.

Table 5. Variation of obliquity angle investigated.

\begin{tabular}{|c|c|}
\hline $\begin{array}{c}\text { Analysis } \\
\text { No. }\end{array}$ & $\begin{array}{c}\text { Angle of } \\
\text { Incidence }\end{array}$ \\
\hline 1 & $0^{\circ}$ \\
\hline 2 & $45^{\circ}$ \\
\hline 3 & $90^{\circ}$ \\
\hline
\end{tabular}


Figure 11 depicts the variation in crush response for $406.4 \mathrm{~mm}$ (16 inches) of penetration into the short hood for the three different angles of incidence. The $45^{\circ}$ incident analysis was positioned such that the initial contact zone was the outside corner of the short hood. The short penetration distance, sixteen inches, over which the crushing force is averaged was chosen to ensure that the effect of the collision post was minimized. It is not surprising that the angled incident analysis case has a slightly elevated mean crush force. The cross-sectional area is continually increasing during penetration of the rigidized object. The predicted stiffness for a normal incident collision is within a few percent of a side impact collision for the short crush distance defined.

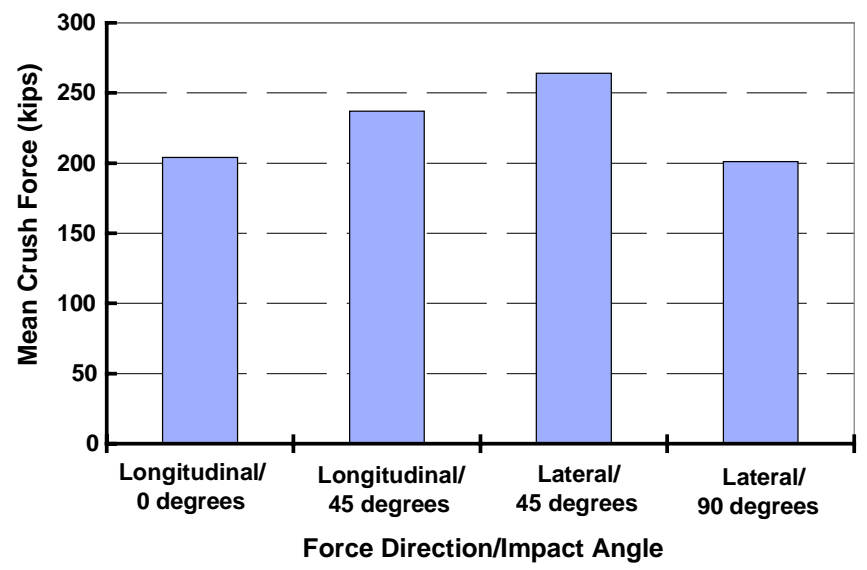

Figure 11. Variation in crush response with obliquity.

\section{Initial Impacting Speed}

The effect of initial impacting speed on the crush response of a typical wide nose locomotive short hood is investigated. A single design concept is developed for these analyses. The approximate hood length is $1.83 \mathrm{~m}$ (72 inches), with a width of $3.05 \mathrm{~m}$ (120 inches), by a height of $1.285 \mathrm{~m}$ (50.6 inches). The hood shell structure is a uniform $9.52 \mathrm{~mm}$ (0.375 inches) thick. A nominal minimum yield strength of $345 \mathrm{MPa}$ (50 ksi) is used for both the shell structure and the collision posts. The collision posts are modeled as described above. Four relative positions are investigated coupled with varying initial impacting speed: (1) $50.8 \mathrm{~mm}$ (2 inches) above the sub-base and $50.8 \mathrm{~mm}$ ( 2 inches) outside the inner corner of the collision post; (2) $50.8 \mathrm{~mm}$ (2 inches) above the sub-base and $355.6 \mathrm{~mm}$ (14 inches) outside the inner corner of the collision post, (3) $381 \mathrm{~mm}$ (15 inches) above the subbase and $203.2 \mathrm{~mm}$ ( 8 inches) outside the inner corner of the collision post; and finally, (4) $762 \mathrm{~mm}$ (30 inches) above the sub-base and $355.6 \mathrm{~mm}$ (14 inches) outside the inner corner of the collision post. The auxiliary node is assigned a mass of $27,215 \mathrm{Kg}(60,000 \mathrm{lbs}$.) and the initial velocity outlined in Table 6 .

Table 6. The speeds applied to auxiliary node to determine changes in crush response with degree of overlap.

\begin{tabular}{|c|c|}
\hline $\begin{array}{c}\text { Analysis } \\
\text { No. }\end{array}$ & $\begin{array}{c}\text { Initial Impacting } \\
\text { Speed }\end{array}$ \\
\hline 1 & $24.14 \mathrm{~km} / \mathrm{h}(15 \mathrm{mph})$ \\
\hline 2 & $48.28 \mathrm{~km} / \mathrm{h}(30 \mathrm{mph})$ \\
\hline 3 & $72.42 \mathrm{~km} / \mathrm{h}(45 \mathrm{mph})$ \\
\hline 4 & $80.47 \mathrm{~km} / \mathrm{h}(50 \mathrm{mph})$ \\
\hline 5 & $96.56 \mathrm{~km} / \mathrm{h}(60 \mathrm{mph})$ \\
\hline
\end{tabular}

Figure 12 depicts the variation in predicted crush response with initial impacting speed and degree of overlap cases (1), (2), (3), and (4). Cases (1) and (2) are sufficiently close to one or two support conditions that there is a high dependence of initial impacting speed on the mean force crush characteristic. Overlap case (1) is near two support conditions and the mode of failure observed, in the finite element animations, are substantial fracture along with some progressive folding. Overlap case (2) has a less stiff support boundary condition then case (1). 
As the rigid object impacts the hood, both a progressive folding and fracture of the hood shell material and lateral torsional buckling of collision post occur. The percentage differences between the largest and smallest initial impacting speed predicted mean crush forces for these two cases are 46 and 19 percent respectively. Overlap cases (3) and (4) are in the transition area of allowable overlap where initial impacting speed does not significantly effect the predicted mean crush force. The percentage differences between the largest and smallest initial impacting speed predicted mean crush forces for these two cases are 18 and 13 percent respectively.
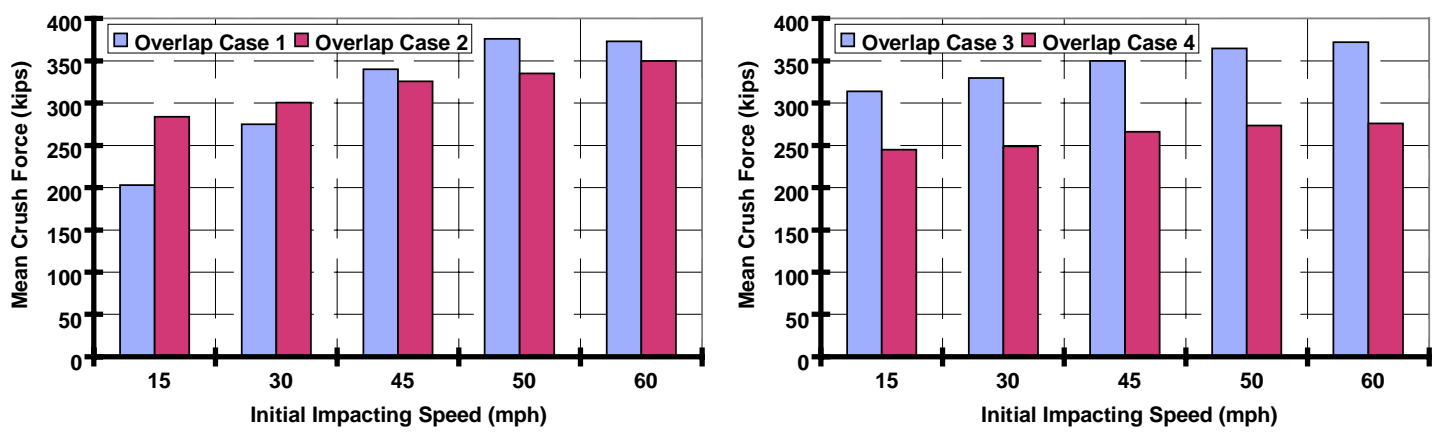

Figure 12. Variation in crush response with initial impact speed for degree of overlap.

\section{CONCLUSIONS}

The force crush characteristics of typical wide nose locomotive hoods are developed and used as input into a companion collision dynamics model used to predict three dimensional motions of the locomotive during an collision scenario where a large rigid object impact the short hood raised above the sub-base and outside the collision posts. A series of design sets have been analyzed using both closed form and finite element analyses to determine the influences of overlap of the impacting object, short hood material, material thickness, obliquity of impact, and impact speed on the crush behavior of locomotive short hood designs. The closed form and finite element analysis agree well within the applicable geometry range of the closed form analyses for the influence of overlap, multiple materials and thickness combinations, and multiple thickness combinations with a uniform hood material.

The closed form analysis neglects the influence of impact speed, and assumes that the short hood is loaded in a uniaxial direction. Overlap is handled by applying a postulated empirical correction factor which accounts for the developed shear band deformations as an alternative method of absorbing energy. The analytical design expression is most applicable for combinations of materials and thicknesses that predict a mean crush force between 667 and $2002 \mathrm{kN}$ (150 and $450 \mathrm{kips}$ ). Outside this range the non-compact solution requires further refinement. The introduction of an equivalent plastic strain to fracture in the definition of the flow stress is currently being investigated and may assist in improving the non-conservative response predicted for excessively thick plate structures.

The finite element analysis shows that the mean crushing force of the short hood is not sensitive to initial impacting speed of the rigid object into a standing locomotive for overlap cases that are sufficiently removed from any support boundary conditions. There is a dependence on initial impacting speed closer to support conditions. However, this dependence is difficult to model with a closed form solution because both material failure and nonlinear deformations processes occur. The average force crush characteristic is not sensitive to the obliquity of the impact for overlap conditions well removed from support boundary conditions. The results of the study also show that the mean crush force of the short hood can be significantly increased over current designs with relatively modest changes in material and plate thickness.

As stated earlier, the purpose of the proposed changes are to provide a benchmark improvement over the conventional design techniques, but there are many other more efficient ways to strengthen the short hood including using stiffeners, designing corner posts, or perhaps using a monocoque design.

Follow-on research efforts planned include:

- Component testing of short hood structures to measure the force/crush behavior of selected locomotive short hood designs,

- Further refinement of the progressive crush analysis for uniform and offset crush conditions for very noncompact sections, 
- Scaled tests of non-compact sections to define changes in crush geometry for both uniform and offset loading conditions,

- New definitions of the flow stress for very non-compact sections introducing a strain to fracture parameter to model failure.

\section{ACKNOWLEDGEMENTS}

The authors would like to thank Mr. John Punwani, Program Manager, Equipment and Operating Practices Division, Office of Research and Development, Federal Railroad Administration and Chairman of the Locomotive Crashworthiness Working Group of the Railway Safety Advisory Committee for his efforts in coordinating activities with the Association of American Railroads, the Railway Progress Institute, the United Transportation Union, and the Brotherhood of Locomotive Engineers. The authors would like to acknowledge the support of Ms. Claire Orth, Chief Equipment and Operating Practices Division, Office of Research and Development, Federal Railroad Administration. Finally, the author's would like to acknowledge the assistance in finite element modeling from their colleagues at Arthur D. Little, Inc., Dr. Ron Mayville and Dr. Richard Stringfellow. This study was performed at the Volpe Center as part of the Rail Equipment Safety Program sponsored by the Office of Research and Development of the Federal Railroad Administration.

\section{REFERENCES}

Abramowicz, W. \& Wierzbicki, T., 1989, “Axial Crushing of Multicorner Sheet Columns,” Journal of Applied Mechanics, Volume 56, pp. 113-120.

Association of American Railroads Technical Services Division, Mechanical Section - Manual of Standards and Recommended Practices, "Locomotive Crashworthiness Requirements, Standard S-580," Adopted: 1989, Revised, 1994.

Hibbit, Karlsson and Sorensen, Inc., 1998, ABAQUS/Explicit Users Manual, Version 5.8.

National Transportation Safety Board, 1995, Amtrak Train 87 Derailment After Colliding with Intermodal Trailer from CSXT Train 176 Selma, North Carolina May 16, 1994, Railroad Accident Report, Adopted March $21,1995$.

Tyrell, D., Severson, K., Marquis, B., Martinez, E., Mayville, R., Rancatore, R., Stringfellow, R., Hammond, R., Perlman, A. B., 1999(a), "Locomotive Crashworthiness Design Modifications Study," Proceedings of the 1999 IEEE/ASME Joint Railroad Conference, April 13-15, 1999, IEEE Catalog Number 99CH36340, ASME RTD Volume 16.

Tyrell, D., Severson, K., Marquis, B., Perlman, A. B., 1999(b), "Simulation of an Oblique Collision of a Locomotive with an Intermodal Container", The Proceedings of the 8th ASME Symposium on Crashworthiness, Occupant Protection, and Biomechanics in Transportation, November 1999, ASME.

Wierzbicki, T. \& Abramowicz, W. , 1983, “On the Crushing Mechanics of Thin-walled Structures,” Journal of Applied Mechanics, Volume 50, pp. 727-739.

Wierzbicki, T., \& Rudolph, S., 1999 Body Shell-Beam Interaction Study, Draft Final Report, U.S. Department of Transportation.

Wierzbicki, T. \& Schneider, F., 1999, The Energy Equivalent Flow Stress: Crashworthiness Application, Report No: 15, Impact \& Crashworthiness Laboratory, MIT. 